\title{
Clinical guideline: management of the first unprovoked epileptic seizure in adults and children
}

\author{
José A. Gien-López', Raymundo A. Cuevas-Escalante², Enrique García-Cuevas³, María R. Márquez-Estudillo ${ }^{4}$, \\ Blanca E. Villaseñor-Anguiano ${ }^{5}$, Raúl Leal-Cantú ${ }^{6}$ and Ramón E. Jiménez-Arredondo ${ }^{7}$
}

${ }^{1}$ Hospital Regional No. 1. IMSS, Mérida, Yucatán; ${ }^{2}$ Hospital Infantil de Tlaxcala, Tlaxcala; ${ }^{3}$ Hospital General Acapulco Guerrero; ${ }^{4}$ Hospital Regional de Puebla, ISSSTE, Puebla; ${ }^{5}$ Hospital General de Zona No. 1. Colima, Colima; ${ }^{6}$ Hospital Civil "Dr. Miguel Silva", Morelia, Michoacán; ${ }^{7}$ Hospital General de Zona No. 1. "Luis Ernesto Miramontes Cárdenas", IMSS Tepic, Nayarit, Mexico City. Mexico.

\begin{abstract}
Unprovoked seizures represent a challenge in the neurological clinical consult. Identifying a first unprovoked seizure is the first step for an adequate medical approach, for which there are different diagnostic tools that help establish the risk of a second seizure, as well as recurrence factors for a first unprovoked epileptic seizure (UES) or diagnose epilepsy. Pharmacological treatment for a first UES and key points for referral to specialists are similarly established, and we move forward to the reference for the next level of medical attention. In this section we also describe nonmedical recommendation for patients and family members after a first UES. This Mexican Guideline was elaborated accounting for the resources and diagnostic tools available in both public and private hospitals in Mexico.
\end{abstract}

Key words: Epilepsy. Unprovoked. Guidelines.

\section{Introduction}

This guideline was developed based on research questions under the PICO method, where questions are presented with their corresponding answer, establishing levels of evidence to offer specific orientation regarding the international recommendations on the related subject matter, seeking the exposure and application of these same management criteria for first unprovoked seizures in children and adults. The final objective of this guide is to aid health-care professionals in solving the initial questions when faced with a patient who has suffered an epileptic seizure (ES) and to make decisions based on the best evidence available.

\section{What are the characteristics of acute symptomatic ESs and unprovoked ESs (UES)?}

An acute symptomatic ES, provoked or reactive, can be defined as seizures presented during the course of a disease which temporarily lowers the threshold of an ES; this type of seizure is not considered epilepsy'.
Correspondence:

Jose Antonio Gien-López

E-mail: neurologiamerida@gmail.com

DOI: 10.24875/RMN.M19000026
Disponible en internet: 12-04-2019 Rev Mex Neuroci. 2019;20(2):76-81 www.revmexneurociencia.com 1665-5044/@ 2019. Academia Mexicana de Neurología A.C. Published by Permanyer México. This is an open access article under the CC BY-NC-ND license (http://creativecommons.org/licenses/by-nc-nd/4.0/). 
For the condition to be considered a provoked ES, the required time span between a cerebral injury and onset of the seizure is 7 days for injuries such as traumatic brain injury (TBI), brain surgery, cerebrovascular disease, and cerebral anoxia and for the acute phase of infections of the central nervous system (CNS); $24 \mathrm{~h}$ for patients with metabolic disorders; and 7-48 $\mathrm{h}$ after the last ingestion of alcohol in patients with abstinence ${ }^{2}$.

An UES is characterized by the lack of temporary or reversible risk factors that lower the threshold to present an $\mathrm{ES}^{3}$. The diagnosis of an ES and epilepsy is based on the patient's medical history, the information obtained during direct questioning when the patient's consciousness is preserved and is able to describe the seizure, or indirect questioning when information is obtained from a first-hand witness of the seizure. A thorough medical history must be obtained to allow the clinician to identify if the event is an ES as well as the type of seizure. This information will also be useful to establish a differential diagnosis between an ES and non-ES such as Psychogenic, syncope or migraine, among other causes ${ }^{4}$. The medical history has always been considered the cornerstone of the approach to any disease, and patients with ES and epilepsy are not the exception ${ }^{5}$.

\section{What are the precipitating risk factors after a first UES?}

A systematic review published in 2015, consisting of 10 randomized control studies, revealed that treatment versus lack of treatment of first ES resulted in early recurrence within 2 years from $21 \%$ to $45 \%$ in the $1^{\text {st }}$ year, respectively ${ }^{6}$. Certain clinical characteristics can determine seizure recurrence. This study demonstrated that the majority of patients with UES are between 16 and 60 years of age, which implies that the age groups before and after this age range have a greater recurrence risk of $2.1 \quad(95 \%$ confidence interval $=1.0-4.3)^{7}$. Other risk factors for seizure recurrence include positive family history, history of febrile seizures, first prolonged seizure, initial suspicion of epilepsy, unknown seizure etiology, abnormal physical examination, and nocturnal seizures in patients aged 1-4 years when compared to patients who remain awake during seizures ${ }^{7}$. A paroxysmal electroencephalogram (EEG), structural injury visible on magnetic resonance imaging (MRI), and prolactin levels are highly specific, yet a poorly sensitive test for ES. Prolactin levels over $36 \mathrm{ng} / \mathrm{mL}$ are highly suggestive of ES; however, these must be measured between 20 min and $4 \mathrm{~h}$ from the onset of the seizure ${ }^{8}$. A lumbar puncture is useful when neuroinfection is suspected ${ }^{8}$.

\begin{tabular}{|l|c|l|}
\hline Evidence & Level & Grade \\
\hline $\begin{array}{l}\text { Brain injury, epileptiform EEG pattern, } \\
\text { abnormal brain imaging, and nocturnal } \\
\text { crisis are factors that increase the degree } \\
\text { of recurrence and aid in the decision to } \\
\text { initiate treatment }\end{array}$ & 1 & A \\
\hline
\end{tabular}

\section{Which diagnostic tests are useful for the diagnosis and prognosis of a first UES?}

EEG - evidence demonstrates that all patients with a first UES should be submitted to an EEG because the data obtained are useful for diagnosing ES when abnormalities are present. Determining the type of ES also helps in identifying the etiology in some cases, and establishing a differential diagnosis from NES ${ }^{8}$. EEG data are also useful in the selection of the anti-epileptic drugs (AED), whenever these are medically indicated. It must be noted, however, that abnormal EEG results without clinical manifestations are not considered epilepsy, and conversely, patients with epilepsy may have a normal EEG?

A meta-analysis of 16 studies established as a seizure recurrence indicator for an UES epileptiform discharges on the EEG (2.0; CI 95\%: 1.6-2.6). If the EEG showed non-epileptiform discharges, there was a recurrence of seizures; however, no statistical significance was found ${ }^{10}$. Records of brain electrical activity within the first $24 \mathrm{~h}$ after the first UES increase the probability of detecting interictal epileptiform discharges (IEDs). The IED is most frequently recorded among temporal epilepsies when compared to extratemporal epilepsies $^{11}$, and they increase seizure recurrence risk.

The EEG must be carried out and interpreted by certified personnel, on patients under hyperventilation and with at least $20 \mathrm{~min}$ of recorded patterns without artifacts. Current guidelines suggest that an EEG is a necessary test for the evaluation and treatment determination after a first $E^{6}{ }^{6}$. EEGs are the most common test used for diagnosing epilepsy. An epileptiform discharge on an EEG was associated with a relative increase in the recurrence rate of ESs when compared to a normal EEG ${ }^{12}$. Patients with an abnormal EEG with epileptiform discharges presented a recurrence risk of $60 \%$ after a first seizure. According to the ILAE 2017, $60 \%$ recurrence risk mandates that the first seizure should be considered epilepsy. The probability of 
finding an abnormality on the EEG is higher after repeat studies, where $39 \%$ of patients presented abnormalities on the first test and $68 \%$ on their third test ${ }^{7}$. Patients with epileptiform discharges have a $77 \%$ recurrence rate on a first UES compared to $47 \%$ if the EEG is normal. These discharges are better detected if the EEG is performed within the first $12 \mathrm{~h}$ after an $\mathrm{ES}^{13}$. According to the ILAE, the recommended window to perform an EEG is within the first $72 \mathrm{~h}$ after a UES and within the first $24 \mathrm{~h}$ after an ES ${ }^{14}$. If EEG results are normal, it is recommended to perform EEG tests during sleep, with sleep deprivation, photostimulation, and repeated tests $^{12-14}$. An unaltered routine EEG does not exclude the presence of an ES. Other studies report that an EEG performed within the first $6 \mathrm{~h}$ after an ES reveals the presence of epileptiform discharges in $67 \%$ of cases, between 6-12 h in 52\%, 12-24 h in 24\%, 24-48 h in $25 \%, 48-72 \mathrm{~h}$ in $22 \%$, and $72-96 \mathrm{~h}$ in $18 \%{ }^{13}$. Based on the previous data, it can be concluded that prompt EEG tests after onset of seizures are more likely to detect epileptiform discharges and their efficacy of detection is progressively reduced in later tests ${ }^{15}$. The American Academy of Neurology (AAN) in 2007 established a time-frame for EEGs within a window of $48 \mathrm{~h}$ after ES onset and up to an average of 15 days afterward ${ }^{13}$.

EEG results from sleep-deprived patients improve the sensibility and specificity of the epilepsy diagnosis. Sleep induced by sleep deprivation is more likely to provoke epileptiform discharges when compared to physiological sleep ${ }^{16}$. Seizure recurrence after a first ES with epileptiform discharges recorded on an EEG was $73.2 \%$, whereas a normal EEG was associated with a $32.8 \%$ recurrence ${ }^{11}$; thus, EEG records with epileptiform graphic patterns were established as a recurrence factor. Seizure recurrence on patients with generalized compared to focal epileptiform discharges was $68.8 \%$ and $75 \%$, respectively ${ }^{13}$. The recommendations of the AAN and the American Epilepsy Society (AES) for patients with a first UES and an EEG with epileptiform discharges are level $A^{6}$.

\section{Neuroimaging}

A computed tomography scan (CT) of the skull is performed in emergency cases on a patient with a first ES; its primary indication is to determine the presence of brain injuries that could cause an ES, such as a stroke or TBI. A CT may also be performed when physical exploration demonstrates a focal neurological deficit, a prolonged altered state of alertness and in febrile patients or with findings that suggest a CNS infection.

MRIs detect more SNC alterations when compared to CT scan; thus, without a need for an emergency image, $M R I$ is the technique of choice ${ }^{12}$. Neuroimaging tests are necessary to predict the probability of recurrence after the first UES ${ }^{6}$. They are indicated with the objective of identifying the etiology of the ES. The advantages of a CT are availability and the speed in which the test is performed, and the results obtained can guide the decision for the need of immediate medical attention, especially in emergency care ${ }^{12}$. Neuroimaging tests have an important value in patients with epilepsy; research shows recurrence rates a year after the first seizure of $59 \%(95 \% \mathrm{Cl} 54-65 \%)$ if patients had an epileptogenic lesion visible on a CT or MRI and $44 \%$ (95\% Cl 41-48\%) in patients without evident lesions by neuroimaging $(p=0.001)^{12}$.

The recurrence rate of UES within 1 year in patients that demonstrated an epileptogenic lesion only by MRI was $67 \%$ compared to $50 \%$ for patients without a visible lesion. The MRI is superior to the CT in detecting epileptogenic abnormalities ${ }^{13}$. If available, an MRI is the preferred neuroimaging technique in patients with a first UES. Neuroimaging tests should be performed following epilepsy protocol and interpreted by neuroradiology specialists.

\section{Evidence}

Children or adults with a first UES should undergo a thorough medical history and examination, followed by at least two diagnostic tests: neuroimaging (CT/MRI) and EEG

A standard EEG is a useful study for the diagnosis of a first UES

An EEG with epileptogenic discharges is the best predictor for recurrence of a first UES, together with an abnormal neurological examination and corresponding etiology

An EEG helps to differentiate between an $E S$ and other events of non-epileptic origin

A routine $E E G$ does not demonstrate evidence of brain abnormalities. A prolonged EEG is useful for the diagnosis of a first UES

The VEEG is a useful test for the diagnosis of a first UES; it predicts a seizure recurrence of $46 \%$ in 12 months and $51 \%$ in 24 months

The CT is a useful test for the diagnosis of a first UES

\section{Level}

Class $\mathrm{I}^{13}$ Class I C.II

Class III $^{15}$

Class $\mathrm{I}^{16}$

Class $I^{16}$

Class III $^{13}$

\author{
(1)
}

Class I ${ }^{16}$

Class II $^{4}$

Class III

Class $\mathrm{I}^{16}$ 


\begin{tabular}{|c|c|}
\hline $\begin{array}{l}\text { Focal lesions are more commonly found on } \\
\text { a CT in adults }(18-34 \%) \text { compared to } \\
\text { children }(0-12 \%) \text {, with the exception of } \\
\text { infants under } 6 \text { months old where } \\
\text { abnormalities are found in } 55 \% \text { of cases } \\
\text { and in adults with HIV in } 28 \% \text { of cases }\end{array}$ & $\begin{array}{l}\text { Class } I^{16} \\
\text { Class } I^{14}\end{array}$ \\
\hline $\begin{array}{l}\text { The following conditions are predictors of } \\
\text { abnormalities found on a CT: altered } \\
\text { neurological examination, infants under } 6 \\
\text { months old, closed TBI, recent } \\
\text { manipulation of ventriculoperitoneal } \\
\text { shunting, cerebral tumor suspicion, } \\
\text { neurocutaneous syndromes, focal onset of } \\
\text { seizure, alcohol abuse history, } \\
\text { cysticercosis, and seizures over } 15 \text { min in } \\
\text { duration }\end{array}$ & Class $1^{14}$ \\
\hline $\begin{array}{l}\text { An MRI is superior to the CT in establishing } \\
\text { the diagnosis of an epileptogenic lesion }\end{array}$ & Class $1^{14}$ \\
\hline $\begin{array}{l}\text { The MRI is the preferred diagnostic test } \\
\text { alongside the EEG in children that present } \\
\text { a first non-febrile seizure }\end{array}$ & Class $\mathrm{I}^{16}$ \\
\hline $\begin{array}{l}\text { The recurrence risk of an UES increases } \\
\text { by } 2.16 \text { ( } 95 \% \mathrm{Cl} 1.44-4.51) \text { if epileptogenic } \\
\text { alterations are found on the EEG and by } \\
2.1 \text { ( } 95 \% \mathrm{Cl} 1.09-5.44) \text { in an abnormal } \\
\text { neuroimaging test }\end{array}$ & Class ${ }^{6}$ \\
\hline Recommendations & Grade \\
\hline $\begin{array}{l}\text { The standard EEG should be considered a } \\
\text { useful test to diagnose UES since it } \\
\text { detects epileptogenic abnormalities in } \\
12-27 \% \text { of cases, and if performed under } \\
\text { sleep deprivation, the probability of } \\
\text { detection increases up to } 58 \%\end{array}$ & Level B \\
\hline $\begin{array}{l}\text { A standard EEG performed within the first } \\
24 \mathrm{~h} \text { of seizure onset detects epileptogenic } \\
\text { abnormalities in } 34-51 \% \text { of cases }\end{array}$ & Level B \\
\hline $\begin{array}{l}\text { A standard EEG detects the same } \\
\text { recurrence risk of a UES as a VEEG }\end{array}$ & Level B \\
\hline $\begin{array}{l}\text { A standard protocol MRI detects } \\
\text { epileptogenic lesions in } 23 \% \text { of cases that } \\
\text { are not detected by CT }\end{array}$ & Level B \\
\hline
\end{tabular}

UES: unprovoked epileptic seizure; CT/MRI: computed tomography/magnetic resonance imaging; EEG: electroencephalogram; ES: epileptic seizure; VEEG: video-electroencephalogram.

\section{What are recurrence factors for first UESs?}

The AAN has described four factors that result in greater seizure recurrence: (1) an EEG with epileptiform abnormalities, (2) cerebral injury such as stroke or TBI, (3) a newly found lesion on neuroimaging, and (4) nocturnal seizures ${ }^{17}$. After a patient suffers a second seizure, the patient has $60 \%$ of recurrence within the $1^{\text {st }}$ year and $70 \%$ recurrence within the $2^{\text {nd }}$ year ${ }^{17}$.
If the seizure is of genetic etiology and the patient has a sibling with seizures, the recurrence risk is $29 \%$. If the seizure is idiopathic with a spike and wave pattern on EEG, the risk increases to $50 \%{ }^{18}$. In children, a 5 -year recurrence risk from the first seizure is $43 \%{ }^{19}$. In the presence of abnormalities on the EEG, the risk increases to over $50 \%$, up to $65 \%{ }^{18}$.

An adult with epileptiform discharges on a routine EEG after a UES has $77 \%$ probability of a second seizure, while in children the probability is $66 \%^{20}$. Children who present a seizure during sleep have a $75 \%$ probability of recurrence within 2 years compared to $49 \%$ in children who did not ${ }^{21}$.

\section{What are the indications for pharmacological treatment?}

Currently, the decision whether to treat a first UES is a matter of controversy. It is generally accepted that AEDs are indicated as of the second UES because recurrence risk is greater $\left(57 \%\right.$ within the $1^{\text {st }}$ year and $73 \%$ within 4 years) $)^{22}$. A study performed by the AAN and the AES based on 10 level $A$ trials determined that the seizure recurrence risk of an adult with a first UES was between $21 \%$ and $45 \%$ within the first 2 years, and the cumulative risk of a second ES was $32 \%$ after a year and $46 \%$ for 5 years ${ }^{1,4}$. In the Multicenter Epilepsy and Single Seizures (MESS) study, it was concluded that the recurrence of a first UES was $39 \%$ within 2 years and $51 \%$ within 5 years ${ }^{2}$.

The probability of presenting an isolated ES is $8-10 \%$ and $3 \%$ of developing epilepsy, revealing an incidence rate of $61 / 100,000$ individuals per year, resulting in a prediction that an estimated 4 million individuals each year will experience a first UES that may be focal or generalized ${ }^{1}$, because $30 \%$ of paroxysmal episodes are inappropriately diagnosed ${ }^{1}$.

To initiate treatment, it is important to confirm the presence of a first UES as there is no doubt that a simulator event is ocurring ${ }^{5,23}$. The degree of certainty of the diagnosis lies in an adequate interrogation, as well as physical and neurological examination, directed diagnostic tests, emphasizing important points of seizure semiology, suspicion of ES or epilepsy establishing a proper differential diagnosis, distinguishing between provoked ES and UES using the definition criteria for epilepsy, and investigating and classifying the type of seizure, as well as the recurrence risk. Treatment should be limited to observation and complementary tests if recurrence risk is low. AED should be initiated if the risk if moderate or high ${ }^{3,24}$. If patients 
have an ES while being alone, complementary laboratory and other diagnostic tests such as the EEG must be performed as soon as possible, because its usefulness is greater in the first $24 \mathrm{~h}$ after the seizure ${ }^{25}$. If epilepsy debut is suspected in subclinical seizures, it must be noted that $<50 \%$ of seizures are detected by a 30 -min routine EEG; however, this detection rate is increased to $90 \%$ if constant monitoring of $24-36 \mathrm{~h}$ is performed ${ }^{26}$. Within the emergency care department, the accepted initial test is a $\mathrm{CT}^{23}$, considering a subsequent MRI, except if the CT demonstrates an important pathology or if the patient must be sedated.

Other tests, such as serum prolactin, are not recommended for the diagnosis of epilepsy; however, it is important to quantify serum electrolytes and glucose to identify potential causes or any comorbidities ${ }^{23}$. An electrocardiogram or referral to a cardiologist must be performed in cases of a doubtful diagnosis. Neuropsychological evaluation is indicated when the MRI demonstrates important alterations or declines in the cognitive areas of the brain. To initiate treatment, the level of certainty of the diagnosis, the degree of alteration in the neurological examination, family history, laboratory and imaging test results, electroencephalography, the side effects of the AED indicated for the type of seizure, quality of life, and cost of treatment must be considered.

The treatment of the first UES reduces short-term recurrence risk but not the long-term prognosis ${ }^{3}$. Thus, it is important to counterweigh AED side effects on recurrence risk when the risk is low $^{3-5,23,24,26}$, considering the possibility if recurrence is greater within the first 3-6 months.

\begin{tabular}{|l|l|l|}
\hline Evidence & Level & Grade \\
\hline $\begin{array}{l}\text { Initial treatment should not be given after a } \\
\text { first seizure except if the recurrence risk is } \\
\text { high or under special circumstances }\end{array}$ & 1 & A \\
\hline $\begin{array}{l}\text { Pharmacological treatment should only be } \\
\text { initiated after the diagnosis of epilepsy is } \\
\text { confirmed }\end{array}$ & 1 & A \\
\hline $\begin{array}{l}\text { The decision to initiate treatment should } \\
\text { be taken by the treating physician together } \\
\text { with the patient or caregiver, after } \\
\text { explaining the recurrence risk, side effects, } \\
\text { and quality of life issues }\end{array}$ & 1 & B \\
\hline $\begin{array}{l}\text { The cornerstone of the diagnosis of an } \\
\text { epileptic seizure is the clinical feature }\end{array}$ & 1 & B \\
\hline $\begin{array}{l}\text { The EEG is useful for the decision to } \\
\text { initiate treatment }\end{array}$ & 1 & B \\
\hline $\begin{array}{l}\text { Neuroimaging tests, such as CT and MRI, } \\
\text { are necessary evaluations of a patient with } \\
\text { an isolated epileptic seizure }\end{array}$ & 1 & A \\
\hline
\end{tabular}

The treatment of the first unprovoked epileptic seizure reduces the risk of relapse but does not affect the long-term prognosis of epilepsy

CT/MRI: computed tomography/magnetic resonance imaging; EEG: electroencephalogram.

\section{What are the reference indications for a first UES?}

Every patient with a first UES must be examined by a neurologist ${ }^{27}$. According to the regional infrastructure, patients must be referred to a secondary or tertiary medical facility if there is any doubt about the type of provoked ES or if there is evidence of cerebral lesion whether it consists of a tumor, hemorrhage, or infection (cysticercosis, toxoplasmosis, or tuberculosis) ${ }^{28}$. Patients that debut with status epilepticus in their first ES must be referred to a specialized facility for treatment as soon as vital signs are stable. Approximately 6-7\% of long debut seizures are considered as status epilepticus $^{29,30}$.

The etiology of a provoked ES was found to be stroke in $34.7 \%, \mathrm{TBI}$ in $34.7 \%$, and infection in the CNS in $30.6 \%$. Conversely, etiology for first UES was a stroke in $68.2 \%$, a TBI in $25 \%$, and CNS infection in $6.8 \%{ }^{31}$.

It is important for patients to also undergo evaluation for seizure simulator conditions, where studies demonstrate that the most common simulator is a syncope reflex $(74 \%)$ and psychogenic seizures $(16 \%)^{32}$. The most common symptoms for reference to a secondary or tertiary medical facility are accompanying neurological manifestations, such as cephalea, immediately after the seizure 28 .

Mortality within the first 30 days from the first provoked ES was $21.4 \%(95 \% \mathrm{Cl}=16.9-26.9 \%)$, compared to $3.4 \%$ for the first UES $(95 \% \mathrm{Cl}=1.4-7.9 \%, \mathrm{p}<0.001)^{31}$.

It has been suggested that in locations where a specialized neurological consult is unavailable, a remote consult by a specialist should be established by telephone or by video conference ${ }^{2}$; this is a common occurrence in subspecialties such as pediatric neurolo$g^{33}$. Every referral to a tertiary health-care facility must include a complete medical history, specifying medication, semiology of neurological signs and symptoms that may aid in classifying the type of seizure, and the directed diagnostic evaluation ${ }^{28}$. 


\begin{tabular}{|l|l|}
\hline Recommendations & Grade \\
\hline $\begin{array}{l}\text { Every patient with a first epileptic seizure must be } \\
\text { evaluated in a secondary health-care facility }\end{array}$ & R-PPE \\
\hline Evidence & \\
\hline Hospitalization criteria for patients with a first UES: & Class III \\
- Under 1 year of age (afebrile) & \\
- Atypical or complex epileptic crisis & \\
- Prolonged postictal state & \\
- Onset status epilepticus & \\
- Meningeal signs & \\
- New neurological deficit (previously absent) & \\
\hline
\end{tabular}

\section{References}

1. Martinez-Juarez IE, Moreno J, Ladino LD, et al. Diagnóstico y tratamiento de la crisis epiléptica única no provocada. Rev Neurol. 2016;63:165-75.

2. Sociedad Andaluza de Epilepsia. Guia Andaluza de Epilepsia. Viguera: Sociedad Andaluza de Epilepsia; 2015.

3. Guía de Práctica Clínica, Diagnóstico y Tratamiento de la Epilepsia en el Adulto en el Primer y Segundo Nivel de Atención. Actualización; 2015.

4. Tao JX, Davis AM. Management of an unprovoked first seizure in adults. JAMA. 2016;316:1590-1

5. Pohlmann-Eden B, Beghi E, Camfield C, Camfield P. The first seizure and its management in adults and children. BMJ. 2006;332:339-42.

6. Krumholz A, Wiebe S, Gronseth GS, et al. Evidence-based guideline: management of an unprovoked first seizure in adults: report of the guideline development subcommittee of the American academy of neurology and the American epilepsy society. Neurology. 2015;84:1705-13.

7. Angus-Leppan H. First seizures in adults. BMJ. 2014;348:g2470.

8. Rosenow F, Klein KM, Hamer HM. Non-invasive EEG evaluation in epilepsy diagnosis. Expert Rev Neurother. 2015;15:425-44.

9. Britton JW, Frey LC, Hopp JL, et al. Electroencephalography (EEG): an Introductory Text and Atlas of Normal and Abnormal Findings in Adults, Children, and Infants. Chicago: American Epilepsy Society; 2016.

10. Berg AT, Shinnar S. The risk of seizure recurrence following a first unprovoked seizure: a quantitative review. Neurology. 1991:41:965-72.

11. Chen T, Si Y, Chen D, et al. The value of 24-hour video-EEG in evaluating recurrence risk following a first unprovoked seizure: a prospective study. Seizure. 2016;40:46-51.

12. Ho K, Lawn N, Bynevelt M, Lee J, Dunne J. Neuroimaging of first-ever seizure: contribution of MRI if CT is normal. Neurol Clin Pract. 2013;3: 398-403.

13. Sofat $P$, Teter B, Kavak KS, Gupta R, Li P. Time interval providing highest yield for initial EEG in patients with new onset seizures. Epilepsy Res. 2016;127:229-32.
14. Askamp J, van Putten MJ. Diagnostic decision-making after a first and recurrent seizure in adults. Seizure. 2013;22:507-11.

15. Gavvala JR, Schuele SU. New-onset seizure in adults and adolescents: a review. JAMA. 2016;316:2657-68.

16. Giorgi FS, Guida M, Caciagli L, et al. What is the role for EEG after sleep deprivation in the diagnosis of epilepsy? Issues, controversies, and future directions. Neurosci Biobehav Rev. 2014;:47:533-48.

17. Fisher RS, Acevedo C, Arzimanoglou A, Bogacz A, Cross JH, Elger CE, et al. Appendix A: summary of evidence-based guideline for clinicians: management of an unprovoked first seizure in adults. Continuum (Minneap Minn). 2016;22:281-2.

18. Rizvi S, Ladino LD, Hernandez-Ronquillo L, Téllez-Zenteno JF. Epidemiology of early stages of epilepsy: risk of seizure recurrence after a first seizure. Seizure. 2017;49:46-53.

19. Shinnar S, Berg AT, Moshe SL, et al. The risk of seizure recurrence after a first unprovoked afebrile seizure in childhood: an extended follow-up. Pediatrics. 1996;98:216-25.

20. Bouma HK, Labos C, Gore GC, Wolfson C, Keezer MR. The diagnostic accuracy of routine electroencephalography after a first unprovoked seizure. Eur J Neurol. 2016;23:455-63.

21. Ramos Lizana J, Cassinello Garciá E, Carrasco Marina LL, et al. Seizure recurrence after a first unprovoked seizure in childhood: a prospective study. Epilepsia. 2000;41:1005-13.

22. Brown JW, Lawn ND, Lee J, Dunne JW. When is it safe to return to driving following first-ever seizure? J Neurol Neurosurg Psychiatry. 2015;86:60-4.

23. NICE Clinical Guideline 137, The Epilepsies: the Diagnosis and Management of the Epilepsies in Adults and Children in Primary and Secondary Care; 2012.

24. Leone MA, Giussani G, Nolan SJ, Marson AG, Beghi E. Immediate antiepileptic drug treatment, versus placebo, deferred, or no treatment for first unprovoked seizure. Cochrane Database Syst Rev. 2016:5:CD007144.

25. Gloss DS, Krumholz A. Managing an unprovoked first seizure in adults. CNS Drugs. 2016;30:179-83.

26. Guía de Practica Clinica IMSS. Diagnóstico y Tratamiento de la Primera Crisis Convulsiva Niñas, Niños y Adolescentes Primero y Segundo Nivel de Atención; 2017.

27. Wilmshurst JM, Gaillard WD, Vinayan KP, et al. Summary of recommendations for the management of infantile seizures: task force report for the ILAE commission of pediatrics. Epilepsia. 2015;56:1185-97.

28. Arkilo D, Griesemer D, Padulsky K, et al. Urgent referrals for seizure evaluation to a tertiary care neurology center: a pilot study. J Child Neurol. 2012;27:885-7.

29. Huff JS, Morris DL, Kothari RU, Gibbs MA, Emergency Medicine Seizure Study Group. Emergency department management of patients with seizures: a multicenter study. Acad Emerg Med. 2001;8:622-8.

30. Krumholz A, Grufferman S, Orr ST, Stern BJ. Seizures and seizure care in an emergency department. Epilepsia. 1989;30:175-81.

31. Brinar V, Bozicevic D, Zurak N, et al. Epileptic seizures as a symptom of various neurological diseases. Neurol Croat. 1991;40:93-101.

32. Jackson A, Teo L, Seneviratne U. Challenges in the first seizure clinic for adult patients with epilepsy. Epileptic Disord. 2016;18:305-14.

33. Millichap JJ, Millichap JG. Child neurology: past, present, and future: part 1: history. Neurology. 2009;73:e31-3. 